serum assays performed to be over $10 \mu \mathrm{g} / \mathrm{ml}$.

Gentamicin is the most active broadspectrum antibiotic available for the treatment of infections due to resistant organisms and as such has an important role to play, especially in specialized units. It is vital that its toxicity is balanced against its therapeutic value. It should probably be reserved for the treatment of severe infections in life-saving situations and in these cases the ototoxicity is of secondary importance. However, there are patients with infections due to resistant bacteria such as Pseudomonas aeruginosa where it is the only effective antibiotic. In these cases and especially where the infection is asymptomatic the ototoxicity is an important factor against its use and the control of treatment is paramount. This control should include serum assays especially where the patient is old or has proved renal impairment and the blood level should be kept under $10 \mu \mathrm{g} / \mathrm{ml}$. As shown by Bulger et al." isolated serum assays may not be sufficient as a single high level may cause damage to the eighth nerve. In the cases described by Cattell et al.11 which were treated with gentamicin, local bladder irrigations might have been more effective than parenteral therapy and would overcome the dangers of toxicity. This form of treatment, however, is impossible on an outpatient basis. It could also be argued that Pseudomonas aeruginosa is a rare cause of pyelonephritis and is usually associated with disease of the lower urinary tract. Even where pre-existing renal disease of a non-obstructive type is present the development of a cystitis due to Pseudomonas aeruginosa is not associated with spread of the organism to involve the renal parenchyma.

Although gentamicin is more ototoxic in animals than the other aminoglycosides, in man it is considerably more active against the commonly isolated pathogenic bacteria and therefore a smaller dose is required to give effective blood concentrations. Synergy between gentamicin and other antibiotics has been shown to occur ${ }^{12}$ and it is possible to reduce the dose of gentamicin without losing antibacterial activity.

The report of Arcieri et al. ${ }^{7}$ suggests that the incidence of ototoxicity of gentamicin is falling and this may be owing to a greater understanding and control of therapy. In a life-saving situation an incidence of possible ototoxicity of up to $5 \%$ is acceptable, and it would be a pity if a statement in a widely read leading article were to curtail its use.I am, etc.,

Wycombe General Hospital,

DONald A. Leigh 1 Black, J., Calesnick, B., Williams, D., and Weinstein, M. J., Antimicr

2 Friedmann, I., Dadswell, J. V., and Bird, E. S foumal of
92, 415. 3 Lundquist, Per-G., and Wersall, J., in Gentamicin: First International Symposium, Paris, Publ. by Essex. 1967, p. 26.
Bulger, R. J.S Sidell, S., and Kirby W. M. N.,
Annals of Internal Medicine. 1963, 59. 593 . Annals of Internal Medicine. 1963, 59. 593 .
Jao, R. L., and Jackson, G. G., fournal of the Jao, R. L., and Jackson, G. G., fournal of the 6 Leigh, D. A., Postgraduate Medical fournal, 1969, Arcieri, G. M., Falco, F. G. Smith, H. M., and
Hobson, L. B., Medical fourmal of Australia, 1970, 1, 30 .

8 Wright, I., Joumal of Pathology, 1969, 98, 129.

Jackson, G. G., 1967, in Gentamicin: First In-
ternational Symposium, Paris, published by ternational Symposium, Paris, published by
Essex, p. 62.
Meyers, R. M., Archives of Otolaryngology, 1970, 92,160 .

11 Cattell, w. R., et al., British Medical fournal,

12 Brumfitt, W., Percival, A., and Leigh, D. A.,
Lancet, 1967, 1, 1289.
Malaria in Southern Europe

SIR,-The case of $P$. vivax malaria described by Drs. R. P. Britt and R. $M$. Hutchinson (24 April, p. 206) is of interest for a number of reasons. Firstly, it indicates once more the possibility of acquiring malaria on holidays on the shores of the Mediterranean. The importance of this apparently first case of malaria reported in this country during the last decade after a visit to southern Europe should not be misinterpreted. It certainly does not imply that the malaria eradication programme of Corsica has not been successful and that special precautions are needed.

Reliable information received through the W.H.O. indicates that autochthonous malaria in southern Europe is a thing of the past. However, this does not exclude the likelihood of sporadic cases of malaria being brought from elsewhere into areas where the disease has been eradicated and infecting local anopheles which may secondarily transmit the disease to some visitors (10 April, pp. 91, 93, and 95). Such episodes have been described before in the United States near the military camps in Georgia (Fort Benning, Fort Stewart) occupied by Army units that returned from the Far East. The fact that the French Foreign Legion has now its base in Corsica may be of interest in this respect and should stimulate an epidemiological study by the local medical authorities.

It seems that about nine days elapsed from the time of the first symptoms of the patient to his admission to the hospita where the correct diagnosis was made. This does not matter a great deal in the case of vivax malaria, but the story might have been different with $P$. falciparum infection, which may develop rapidly with serious consequences. The possibility of malaria in any febrile patient who has been on holiday in any subtropical or tropical area should always be kept in mind, as emphasized by Maegraith. ${ }^{2}$ Indocti discant et ament meminisse periti!-I am, etc.,

\section{J. Bruce-ChwatT}

London School of Hygiene and Tropical Medicinc. London $\mathbf{W} . \mathbf{C . 1}$

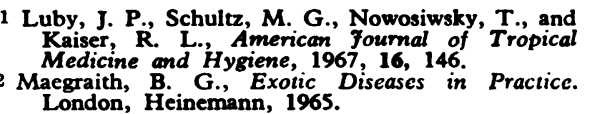
Maegraith, B. G., Exotic Diseases in Practice. London, Heinemann, 1965.

\section{New Spinal Manometer}

SIR,-The general introduction of prepacked trays from a central sterile supply department has brought problems in the provision of an adequate spinal manometer. The older glass manometer, designed for use with Greenfield's needle, is relatively expensive, difficult to clean, easily broken, and too long to be included satisfactorily in a standard pack. The recent interim report of the steering committee on standardization of supplies for central sterile supply departments has specified, in its addendum on pack content, that a disposable manometer and tubing be included in a lumbar puncture set.

With these points in mind, a sectional plastic manometer has been developed at this hospital which meets all the above objections. The manometer, made of clear autoclavable plastic, comes in two $200 \mathrm{~mm}$

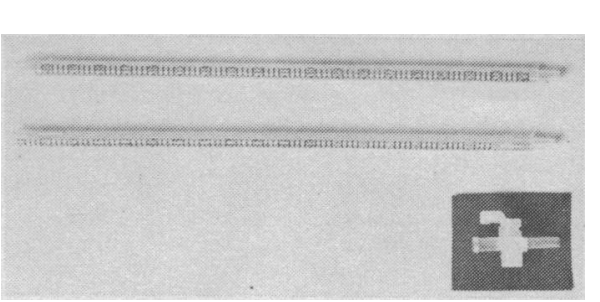

sections calibrated from 30-200 and 201-400 mm. These fit together by a standard Luer connexion and may in turn be fitted to a three way tap, again with Luer fittings. The whole may then be used with any standard lumbar puncture needle, whether disposable -as recommended by the steering committee-or reusable. The unit may be sterilized by autoclaving and can thus be included in a standard pack, or may be supplied presterilized by irradiation, in a separate double wrap pack. A further advantage of the device is that pressures in excess of $400 \mathrm{~mm}$ may simply be measured by adding one or more units to the standard pair; an application which may prove useful in the measurement of central venous pressure. The unit, which has for some months been included in the lumbar puncture packs in use at this hospital, has proved entirely satisfactory.

My thanks are due to Mr. Meredith of Rocket Ltd. for his help in the development of the manometer. The unit complete with three way tap is available from Rocket of London Ltd., Imperial Way, Watford, Herts, price about 25p. -I am, etc.

Middlesex Hospital,

A. E. Booth

London $\mathbb{W} .1$

Wound Dehiscence after Caesarean Section

SIR,-I read with interest the article by $\mathrm{Dr}$. James Mowat and Dr. John Bonnar (1 May, p. 256). Few would dispute the more efficacious healing of the transverse as opposed to the vertical abdominal incision. The former, however, has one disadvantage; its performance is time consuming. To obviate this demerit and yet provide a: sound scar I have over several years of general surgical and gynaecological practice (including many caesarean sections) used a mid-line incision with repair of peritoneum and rectus sheath with monofilamentous nylon (or Mersilk). The subcutaneous layer is coapted with a continuous 00 catgut suture; to avoid fat necrosis, small tissue bites are taken. The skin is closed with a continuous eversion mattress suture and a small tissue "flag drain" placed at the lower end and left in situ for 24 hours (the "flag" ensures non-disappearance). Before closure haemostasis has been obtained by the application of pressure forceps, which are left in situ for several minutes; diathermy and multiple buried catgut knots are avoided.

With this method I find wound dehiscence rare.-I am, etc.,

A. W. BANKS

Macclesfield,

SIR,-In the article "Abdominal Wound Dehiscence after Caesarean Section" (1 May, p. 256), it would seem highly significant that 21 patients out of the 50 patients whose 